\section{Regards sur l'économie allemande}

Bulletin économique du CIRAC

$75 \mid 2006$

Varia

\title{
Vulgarisation économique
}

KAMINSKI Hans (ed), oec. Ökonomie. Grundfragen wirtschaftlichen Handelns / PIPER Nikolaus, Geschichte der Wirtschaft erzählt von N. Piper / SMITH David, Wirtschaftswissen leicht serviert. Die perfekte Einführung in die Welt der Wirtschaft

\section{(2)enEdition}

\section{Journals}

Édition électronique

URL : http://journals.openedition.org/rea/503

DOI : $10.4000 /$ rea. 503

ISBN : 978-2-8218-0846-1

ISSN : 1965-0787

Éditeur

CIRAC

\section{Édition imprimée}

Date de publication : 1 mars 2006

ISSN : 1156-8992

Référence électronique

"Vulgarisation économique », Regards sur l'économie allemande [En ligne], 75 | mars 2006, document 11, mis en ligne le 24 avril 2008, consulté le 22 septembre 2020. URL : http://journals.openedition.org/ rea/503 ; DOI : https://doi.org/10.4000/rea.503

Ce document a été généré automatiquement le 22 septembre 2020.

(c) CIRAC 


\section{Vulgarisation économique}

KAMINSKI Hans (ed), oec. Ökonomie. Grundfragen wirtschaftlichen Handelns / PIPER Nikolaus, Geschichte der Wirtschaft erzählt von N. Piper / SMITH David, Wirtschaftswissen leicht serviert. Die perfekte Einführung in die Welt der Wirtschaft

\section{RÉFÉRENCE}

KAMINSKI Hans (ed), oec. Ökonomie. Grundfragen wirtschaftlichen Handelns, Westermann, Braunschweig, 2005, $552 \mathrm{p}$.

PIPER Nikolaus, Geschichte der Wirtschaft erzählt von N. Piper, Beltz \& Gelberg, Bâle, 2005, 206 p.

SMITH David, Wirtschaftswissen leicht serviert. Die perfekte Einführung in die Welt der Wirtschaft, Murmann, Hamburg, 2005, 320 p.

Les Allemands manqueraient-ils de connaissances en économie? On peut se le demander quand on voit l'abondante littérature de vulgarisation qui paraît en ce moment. Il est vrai que l'économie est, outre-Rhin aussi, le parent pauvre de l'enseignement scolaire général. Mais de ce fait, les Allemands n'ont qu'une compréhension insuffisante des mécanismes à l'œuvre dans leur environnement immédiat et jusque dans leur vie quotidienne. Pour combler ces lacunes, le rédacteur en chef économique du quotidien Süddeutsche Zeitung (PIPER) publie une édition revue et augmentée de son "Economie racontée aux enfants" - savoureusement et magistralement à la fois. L'économie n'a rien d'aride, comme le démontre un autre ouvrage (SMITH), écrit avec un humour très british (l'auteur est journaliste économique au Sunday Times) et construit sur le mode d'un livre de cuisine. Les gros appétits y trouveront des plats de résistance («L'autre menu: Marx», ou "Cuisiner avec Keynes »); les lecteurs pressés dégusteront avec délices son glossaire sous forme de petites bouchées bien appétissantes. Dans un registre plus classique, le directeur de l'Institut de Formation économique et technique d'Oldenburg (KAMINSKI) présente un manuel scolaire, publié chez l'éditeur spécialisé Westermann. Il s'adresse aux jeunes en apprentissage ou dans le cycle long du secondaire, leur proposant une introduction 
vivante aux lois de l'économie dans l'objectif de leur faire comprendre les grands enjeux du monde présent. Ce manuel très vivant s'inscrit dans la continuité d'une action qui avait été menée en partenariat public-privé: Wirtschaft in die Schule! («L'économie à l'école!») et qui visait à diffuser la connaissance de l'économie en milieu scolaire. Toute une série d'actions analogues existe en Allemagne, le plus souvent d'initiative privée, comme la publication régulière de documents pédagogiques par l'institut IW de la Fédération BDI. (ib) 